УДК 616.89:661.834:547.475.2

Для цитирования: Лосенков И.С., Плотников Е.В., Епимахова Е.В. Цитотоксический и прооксидантный эффекты аскорбата лития in vitro. Сибирский вестник психиатрии и наркологии. 2018; 1 (98): 24-29. https://doi.org/10.26617/1810-31112018-1(98)-24-29

\title{
Цитотоксический и прооксидантный эффекты аскорбата лития in vitro
}

\section{Лосенков И.С. ${ }^{1}$, Плотников Е.В. ${ }^{1,2}$, Епимахова Е.В. ${ }^{1}$}

${ }^{1}$ НИИ психического здоровья, Томский наџиональный исследовательский медицинский изентр Российской академии наук Россия, 634014, Томск, ул. Алеутская, 4

${ }^{2}$ Исследовательская икола химических и биомедицинских технологий, Томский политехнический университет Россия, 634050, Томск, пр. Ленина, 30

\section{PEЗЮME}

В настоящее время ведется разработка и изучение новых комплексных препаратов лития с антиоксидантными свойствами. Перспективным в этом отношении может быть аскорбат лития. Проведена оценка цитотоксичности аскорбата лития и аскорбиновой кислоты, а также изучено их влияние на окислительный стресс на клеточной модели мононуклеаров периферической крови. Обнаружен выраженный цитотоксический эффект аскорбата лития и аскорбиновой кислоты, заключающийся в повышении процента клеток как в состоянии раннего апоптоза, так и в состоянии позднего апоптоза/некроза. Продемонстрирована индукция окислительного стресса (повышение процента клеток с активными формами кислорода) в присутствии этих соединений. Таким образом, в экспериментах in vitro в используемых концентрациях аскорбат лития не является антиоксидантом, то есть для оценки аскорбата лития как потенциального фармакологического препарата требуются дальнейшие исследования как на других клеточных культурах in vitro, так и в экспериментах in vivo.

Ключевые слова: литий, аскорбата лития, аскорбиновая кислота, окислительный стресс, цитотоксичность, апоптоз.

\section{ВВЕДЕНИЕ}

Литиевые соли, внедренные в психиатрию в середине прошлого века, до сих пор широко используются в качестве нормотимиков - стабилизаторов настроения [1]. Наиболее распространенным препаратом остается карбонат лития.

Механизм действия лития весьма сложен и продолжает активно изучаться. Достоверно показано, что литий включается в целый ряд механизмов внутриклеточной регуляции. Ключевой мишенью лития является ингибирование киназы гликогенсинтазы 3 (GSK-3)[2]. Вместе с тем литий обладает антиапоптотическим действием и, вероятно, влияет на Akt1/PI3K/mTOR путь [3]. Помимо этого литий обладает выраженной нейропротективной активностью in vivo [4].

В последнее время появились публикации о комплексном защитном действии ионов лития при индуцированном окислительном стрессе $[5,6]$. Развитие окислительного стресса отмечается при ряде соматических и психических патологий, в частности показано истощение антиоксидантных систем при алкоголизме [7, 8]. Поэтому применение антиоксидантов в комплексной терапии патогенетически обосновано.

В настоящее время ведется разработка и изучение новых комплексных препаратов лития с антиоксидантными свойствами [9]. Показано, что среди изученных соединений выраженной антиоксидантной активностью обладает аскорбат лития, который в то же время характеризуется нейропротекторными свойствами [10] и способен защищать белки и липиды плазмы крови от повреждающего действия этанола [11].
В этой связи важной задачей является оценка биологической активности соединений лития, в частности их влияние на окислительный стресс и цитотоксичность в клеточных культурах. В данной работе впервые проведена оценка цитотоксического действия аскорбата лития и изучен его эффект на продукцию активных форм кислорода в культуре мононуклеаров периферической крови человека.

Цель исследования - изучение цитотоксического и прооксидантного эффектов аскорбата лития in vitro.

\section{МАТЕРИАЛЫ И МЕТОДЫ}

\section{Реактивы}

Необходимое для эксперимента количество аскорбата лития синтезировано на кафедре физической и аналитической химии Томского политехнического университета. Синтез произведен из химически чистых реагентов карбоната лития и аскорбиновой кислоты (Sigma-Aldrich, Германия). Аскорбат лития перекристаллизовывали и использовали в дальнейших опытах.

Получение клеточной культуры мононуклеаров крови человека

В исследовании использовали кровь 9 здоровых лиц - 3 мужчин и 6 женщин в возрасте от 25 до 54 лет, медиана - 35,0 (25,0-53,0). Кровь получена из локтевой вены в пробирки с гепарином натрия системы однократного применения Vacutainer («Becton Dickinson», США). Мононуклеары выделяли из крови путем центрифугирования на градиенте плотности фиколла $\left(\rho=1,077 \quad \Gamma / \mathrm{cm}^{3}\right)$ («Sigma-Aldrich», США) по стандартной методике [9]. Полученные клетки ресуспендировали в среде RPMI-1640. Клеточную суспензию сразу использовали в экспери- 
менте.

\section{Изучение ичитотоксической активности}

Исследование цитотоксичности соединений в отношении мононуклеаров периферической крови было проведено с использованием набора реактивов «Annexin V \&DeadCellAssayKit» (MerckMillipore, Германия) на проточном цитолюориметре «MuseCellAnalyzer» (MerckMillipore, Германия). Клетки в нижнем левом углу гейтескаттерограммы считали за живые, клетки в нижнем правом - в ранней стадии апоптоза (early apoptosis), в верхнем правом - в поздней стадии апоптоза/некрозе (late apoptosis/dead), в верхнем левом гейте - мертвые клетки (dead cells), в состоянии некроза.

Исследование окислительного стресса

Влияние соединений на окислительный стресс исследовали с использованием набора реагентов «Oxidativestress» (MerckMillipore, Германия) на проточном цитолюориметре «MuseCellAnalyzer» (MerckMillipore, Германия). Левый пик графика (гейт M1) считали как процент клеток, свободных от активных форм кислорода, и обозначали как $\operatorname{ROS}(-)$, правый пик графика (гейт M2) считали как процент клеток, содержащих активные формы кислорода, $\operatorname{ROS}(+)$.

C целью оценки цитотоксической активности и окислительного стресса мононуклеары инкубировали в присутствии аскорбата лития или аскорбата в течение 24 часов при $37^{\circ} \mathrm{C}$ в среде $5 \%$ углекислого газа. В исследовании использованы следующие концентрации: 0,5, 1 или 2 ммоль/л конечной концентрации ионов лития в лунке.

Статистическая обработка результатов проведена с помощью программы SPSS (версия 20.0). Рассчитывали медиану, первый и третий квартили.
Для сравнения количественных переменных использовались критерии Манна-Уитни и КраскелаУоллиса. Различия считали статистически достоверными при уровне значимости $\mathrm{p}<0,05$.

\section{РЕЗУЛЬТАТЫ}

Была проведена оценка цитотоксического действия аскорбата лития. Данные о проценте клеток в состоянии апоптоза и некроза представлены в таблице 1 и на рисунке 1.

Т а б л и ц а 1

Уровень клеточной гибели (\%) при воздействии аскор-
бата лития - Ме $\left(\mathbf{Q}_{1}-\mathbf{Q}_{3}\right)$ (критерий Манна-Уитни)
\begin{tabular}{|c|c|c|c|}
\hline Показатель & \multicolumn{3}{|c|}{ Группа } \\
\cline { 2 - 4 } & $\begin{array}{c}\text { Ранний апопто3 } \\
\text { (early apoptosis) }\end{array}$ & $\begin{array}{c}\text { Поздний } \\
\text { aпопто3/некро3 } \\
\text { (late } \\
\text { apoptosis/dead) }\end{array}$ & $\begin{array}{c}\text { Некро3 } \\
\text { (dead) }\end{array}$ \\
\hline $\begin{array}{c}\text { Интактные } \\
\text { клетки }\end{array}$ & 13,30 & 12,88 \\
$(10,20-13,45)$ & $(10,20-13,45)$ & 0 \\
\hline 0,5 ммоль/л & $31,94^{1}$ & $61,73^{4}$ & 0,08 \\
аскорбата лития & $(30,55-35,24)$ & $(52,85-67,36)$ & $(0-0,2)$ \\
\hline 1 ммоль/л & $28,0^{2}$ & $64,93^{5}$ & 0,05 \\
аскорбата лития & $(27,10-34,29)$ & $(52,98-72,07)$ & $(0-4,0)$ \\
\hline 2 ммоль/л & $28,80^{3}$ & $69,30^{6}$ & 0,05 \\
аскорбата лития & $(25,50-34,64)$ & $(50,77-72,22)$ & $(0-0,9)$ \\
\hline
\end{tabular}

П р и м е ч а н и е. $1,4,5-\mathrm{p}<0,001$ по сравнению с интактными клетками; 2 - $\mathrm{p}=0,004$ по сравнению с интактными клетками; 3 - $\mathrm{p}=0,001$ по сравнению с интактными клетками; 6 $\mathrm{p}=0,006$ по сравнению с интактными клетками.

Был обнаружен цитотоксический эффект аскорбата лития, заключающийся в статистически значимом ( $<<0,05)$ повышении процента клеток в состоянии раннего апоптоза и позднего апоптоза/некроза при инкубации с данным соединением. Дозозависимого эффекта аскорбата лития на вышеперечисленные параметры не найдено ( $>>0,05)$.

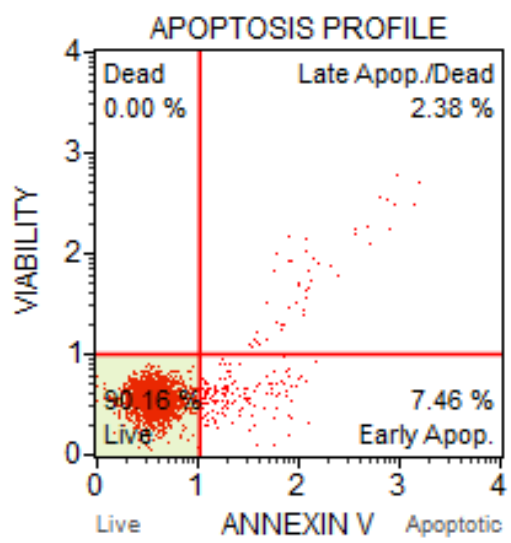

a

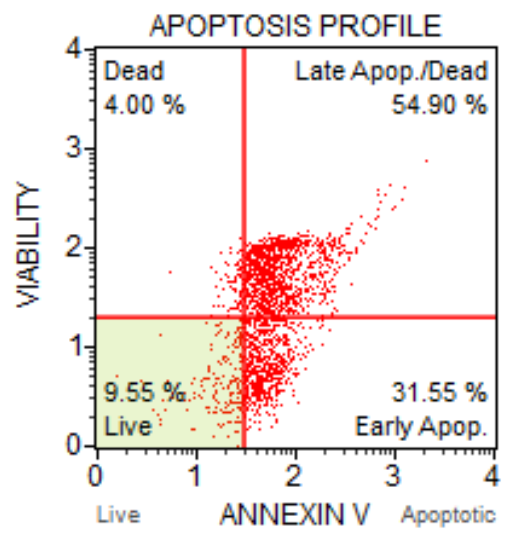

6

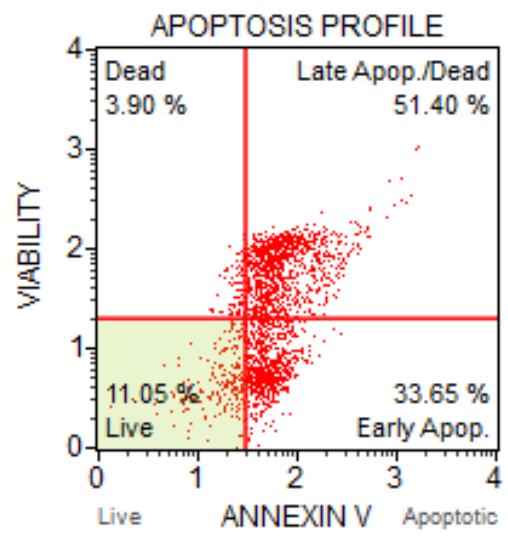

B

Р и с у н о к 1. Цитотоксичность аскорбата лития и аскорбиновой кислоты в эксперименте: (а) интактная культура, (б) культура в присутствии 2,0 ммоль/л аскорбата лития, (в) культура в присутствии 2,0 ммоль/л аскорбиновой кислоты

По результатам эксперимента нами была выдвинута гипотеза и том, что цитотоксический эффект аскорбата лития может реализоваться через действие аскорбат-аниона. Для подтверждения данной гипотезы проведена оценка цитотоксичности аскорбиновой кислоты (табл. 2 и рис. 1).
Как видно из таблицы 2 и рисунка 1, аскорбиновая кислота обладала выраженным цитотоксическим действием, проявляющимся в статистически значимом ( $<<0,05)$ повышении процента клеток в состоянии апоптоза и некроза. Не было обнаружено дозо- 
зависимого цитотоксического эффекта данного соединения $(\mathrm{p}>0,05)$.

Т а б ли ц а 2 Уровень клеточной гибели (\%) при воздействии аскорбата лития - Ме $\left(Q_{1}-Q_{3}\right)$ (критерий Манна-Уитни)

\begin{tabular}{|c|c|c|c|}
\hline Показатель & \multicolumn{3}{|c|}{ Группа } \\
\cline { 1 - 4 } & $\begin{array}{c}\text { Paнний апопто3 } \\
\text { (early apoptosis) }\end{array}$ & $\begin{array}{c}\text { Поздний } \\
\text { апоптоз/некро3 } \\
\text { (late } \\
\text { apoptosis/dead) }\end{array}$ & $\begin{array}{c}\text { Некро3 } \\
\text { (dead) }\end{array}$ \\
\hline $\begin{array}{c}\text { Интактные } \\
\text { клетки }\end{array}$ & $\begin{array}{c}13,30 \\
(10,20-13,45)\end{array}$ & $\begin{array}{c}12,88 \\
(10,20-13,45)\end{array}$ & 0 \\
\hline $\begin{array}{c}0,5 \text { ммоль/л аскор- } \\
\text { биновой кислоты }\end{array}$ & $\begin{array}{c}30,55^{1} \\
(26,35-37,58)\end{array}$ & $\begin{array}{c}60,27^{4} \\
(56,20-63,04)\end{array}$ & $\begin{array}{c}0,10 \\
(0-5,51)\end{array}$ \\
\hline $\begin{array}{c}1 \text { ммоль/л аскор- } \\
\text { биновой кислоты }\end{array}$ & $\begin{array}{c}34,90^{2} \\
(16,32-38,44)\end{array}$ & $\begin{array}{c}54,97^{5} \\
(47,28-61,60)\end{array}$ & $\begin{array}{c}1,71 \\
(0-7,71)\end{array}$ \\
\hline 2 ммоль/л аскор- & $\begin{array}{c}29,39^{3} \\
\text { биновой кислоты }\end{array}$ & $\begin{array}{c}62,60^{6} \\
(26,11-40,30)\end{array}$ & 0 \\
\hline
\end{tabular}

П р и м е ч а н и е. $1,4,5,6-p<0,001$ по сравнению с интактными клетками; 2, 3 - $\mathrm{p}=0,001$ по сравнению с интактными клетками.

Известно, что аскорбиновая кислота способна выступать как в качестве восстановителя (антиоксидант), так и качестве окислителя (прооксидант). Нами было выдвинуто предположение, что цитотоксический эффект аскорбат-аниона может быть опо- средован индукцией окислительного стресса. Произведена оценка содержания активных форм кислорода в мононуклеарах периферической крови при действии аскорбата лития и аскорбиновой кислоты. Данные представлены в таблице 3 и на рисунке 2.

Т а б ли ц а 3

\begin{tabular}{|c|c|}
\hline \multicolumn{2}{|c|}{$\begin{array}{c}\text { Содержание клеток с активными формами кислорода } \\
(\%) \text { при воздействии аскорбата лития и аскорбиновой } \\
\text { кислоты - Ме }\left(Q_{1}-Q_{3}\right) \text { (критерий Манна-Уитни). }\end{array}$} \\
\hline Показатель & $\begin{array}{c}\text { Клетки с активными } \\
\text { формами кислорода, }(\%)\end{array}$ \\
\hline Интактные клетки & $\begin{array}{c}13,0 \\
(6,45-23,68)\end{array}$ \\
\hline 0,5 ммоль/л аскорбата лития & $\begin{array}{c}83,10^{1} \\
(80,88-90,46)\end{array}$ \\
\hline 1 ммоль/л аскорбата лития & $\begin{array}{c}83,32^{2} \\
(80,22-89,13)\end{array}$ \\
\hline 2 ммоль/л аскорбата лития & $\begin{array}{c}90,58^{3} \\
(81,55-91,41)\end{array}$ \\
\hline 0,5 ммоль/л аскорбиновой кислоты & $\begin{array}{c}84,57^{4} \\
(71,74-90,23)\end{array}$ \\
\hline 1 ммоль/л аскорбиновой кислоты & $\begin{array}{c}85,93^{5} \\
(82,44-88,89)\end{array}$ \\
\hline 2 ммоль/л аскорбиновой кислоты & $\begin{array}{c}87,19^{6} \\
(84,81-88,87)\end{array}$ \\
\hline
\end{tabular}

П р и м е ч а н и е. $1,2,3,4,5,6-$ p<0,001 по сравнению с интактными клетками.

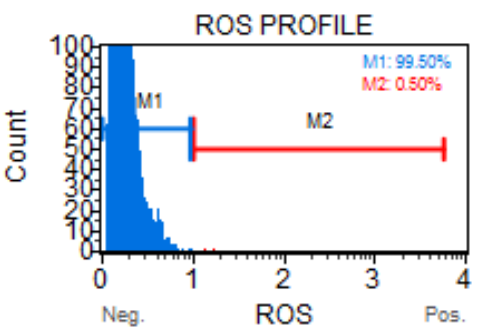

a

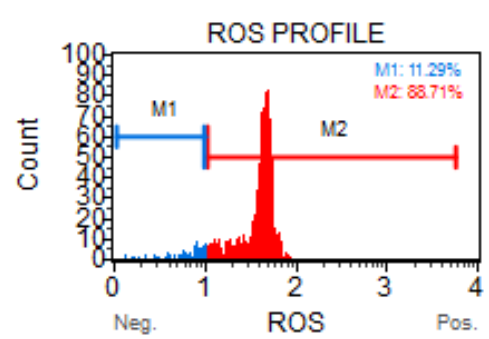

6

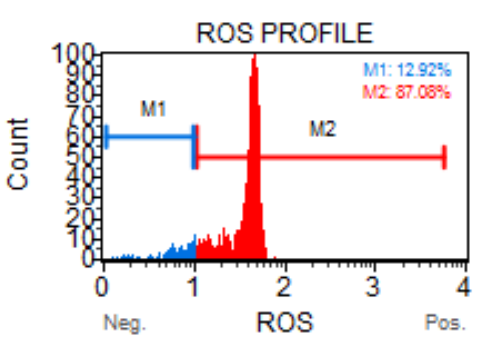

B

\section{P и с у н о к 2 . Содержание активных форм кислорода (ROS) в интактных мононуклеарах периферической крови (а) и при действии аскорбата лития (б) и аскорбиновой кислоты (в) Гейт M1 - ROS-негативные клетки, гейт M2 - ROS-позитивные клетки.}

Как видно из таблицы 3 и рисунка 2, как аскорбат лития, так и аскорбиновая кислота обладала выраженным прооксидантным действием, статистически значимо ( $<0,001)$ повышая содержания клеток с активными формами кислорода. Дозозависимого эффекта данных соединений в отношении продукции активных форм кислорода не было обнаружено $(\mathrm{p}>0,05)$.

\section{ОБСУЖДЕНИЕ}

Таким образом, в нашем исследовании обнаружена выраженная цитотоксичность аскорбата лития, реализуемая прооксидантным действием аскорбатаниона. Исследование уровня окислительного стресса в культуре клеток полностью коррелирует с уровнем цитотоксичости в культуре, что подтверждает окислительный пусковой механизм данного процесса. Аналогичные результаты получены для аскорбиновой кислоты в тех же дозах, что подтверждает основное действие аскорбат-аниона, однако действие иона лития в данном случае не вносит существенного вклада в цитотоксический эффект, наблюдаемый в культуре мононуклеаров периферической крови.

Традиционно считается, что аскорбиновая кислота и аскорбат-анион являются антиоксидантами, обладая выраженными восстановительными свойствами, метаболизируясь до дегидроаскорбиновой кислоты [10] (рис 3). 


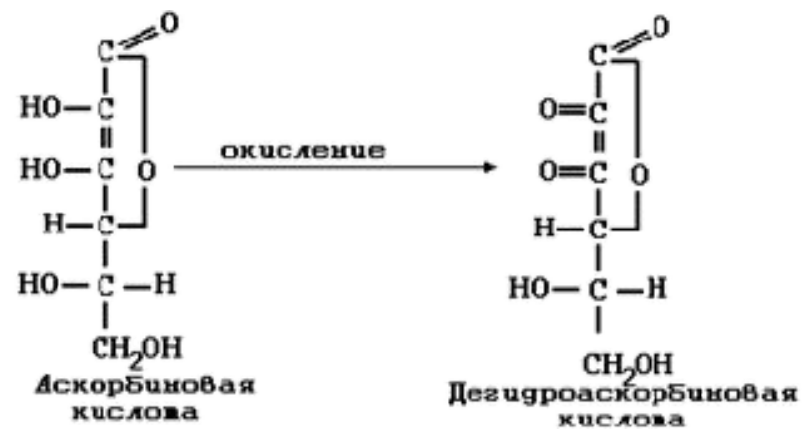

Р и с у н о к 3 . Окисление аскорбиновой кислоты стресса при действии аскорбата аниона. В ряде исследований доказано, что аскорбиновая кислота может запускать окислительный стресс. Продемонстрировано, что этот процесс катализируется ионами металлов: железо (III) [11], медь (II) [12] (рис. 4), кадмий (II) и никель (II) [13]. Результатом этого процесса является образование гидроперекиси водорода. В здоровых клетках организма экспрессия антиоксидантных ферментов достаточна, чтобы нейтрализовать перекись водорода и предотвратить индукцию окислительного стресса.

Нами было показана индукция окислительного

$$
\begin{gathered}
\text { Ascorbate }+\mathrm{Cu}^{2+}+\mathrm{O}_{2}+2 \mathrm{H}^{+} \rightarrow \\
\text { Dehydroascorbate }+\mathrm{Cu}^{+}+\mathrm{H}_{2} \mathrm{O}_{2} \\
\mathrm{Cu}^{+}+\mathrm{H}_{2} \mathrm{O}_{2} \rightarrow \mathrm{Cu}^{2+}+\mathrm{OH}^{+}+\mathrm{OH}^{-}
\end{gathered}
$$

Р и с у н о к 4 . Окисление аскорбиновой кислоты в присутствием ионов меди (II) с образованием гидроперекиси водорода

N.H. Riordan et al. (1995) предположили, что acкорбиновая кислота в дозах, превышающих физиологические, может быть использована как препарат химиотерапии ввиду того, что в опухолевых клетках понижена экспрессия антиоксидантных ферментов [14]. Вследствие этого перекись, образованная окислением аскорбиновой кислоты, слабо утилизируется, приводя к индукции окислительного стресса и цитотоксичности аскорбат-аниона.

Аскорбат лития, являясь солью аскорбиновой кислоты, сохраняет присущие ей антиоксидантные свойства. Ранее была установлена высокая активность аскорбата лития в отношении кислородных радикалов [15]. Однако это исследование было выполнено на плазме крови. Так же, как было сказано выше, аскорбат лития обладает нейропротекторным свойствами in vivo [8]. Вероятно, что в изолированной культуре мононуклеаров, культивируемых в среде RPMI-1640, предназначенной для работы с лимфоидными клетками, не достигается достаточный уровень экспрессии антиоксидантных ферментов, способных утилизировать гидроперекись водорода и, как следствие, нивелировать прооксидантные свойства аскорбат-аниона.

\section{ЗАКЛЮЧЕНИЕ}

Установлен цитотоксический эффект аскорбата лития в отношении мононуклеаров периферической крови. Данный эффект объясняется проокислительным действием аскорбат-аниона. Цитотоксического и прооксидантного эффектов ионов лития не выявлено. Для оценки аскорбата лития как потенциального фармакологического препарата требуются дальнейшие исследования как на других клеточных культурах in vitro, так и в экспериментах in vivo.

\section{КОНФЛИКТ ИНТЕРЕСОВ}

Авторы заявляют об отсутствии конфликта интересов в связи с публикацией данной статьи.

\section{ИСТОЧНИК ФИНАНСИРОВАНИЯ}

Исследование выполнено при поддержке гранта Российского научного фонда (проект №17-75-20045) «Действие органических солей лития на клетки и плазму крови больных с расстройствами аффективного спектра и синдромом зависимости».

\section{СООТВЕТСТВИЕ ПРИНЦИПАМ ЭТИКИ}

Исследование проведено с соблюдением норм современной биомедицинской этики и этических стандартов, разработанным в соответствии с Хельсинской декларацией ВМА (протокол заседания этического комитета НИИ психического здоровья, Томский национальный исследовательский медицинский центр Российской академии наук № 103 от 23.10.2017).

\section{ЛИТЕРАТУРА}

1. Машковский М.Д. Лекарственные средства: в двух частях. Часть 1. 12-е изд. М.: Медицина; 1986: 544.

2. Freland L., Beaulieu J.M. Inhibition of GSK3 be lithium, from single molecules to signaling networks. Frontiers in molecular neuroscience. 2013; 5: 9-15.

3. Wu J., Zhu D., Zhang J., Li G., Liu Z., Sun J. Lithium protects against methamphetamine-induced neurotoxicity in PC12 cells via Akt/GSK3b/mTOR pathway. Biochem. Biophys. Res. Commun. 2013; 465: 368-373.

4. Zheng J., Liu Z., Li W., Tang J., Zhang D., Tang X. Lithium posttreatment confers neuroprotection through glycogen synthase kinase-3 $\beta$ inhibition in intracerebral hemorrhage rats. J. Neurosurg. 2017; 127: 716-724.

5. Saberzadeh J., Omrani M., Takhshid M.A. Protective effects of nimodipine and lithium against aluminum-induced cell death and oxidative stress in PC12 cells. Iran J. Basic. Med. Sci. 2016; 19: 1251-1257.

6. da-Rosa D.D., Valvassori S.S., Steckert A.V., Ornell F., Ferreira C.L., Lopes-Borges J. Effects of lithium and valproate on oxidative stress and behavioral changes induced by administration of m-AMPH. Psychiatry Res. 2012; 198: 521-526. 
7. Plotnikov E., Korotkova E., Voronova O., Sazhina N., Petrova E., Artamonov A., Chernyavskaya L., Dorozhko E. Comparative investigation of antioxidant activity of human serum blood by amperometric, voltammetric and chemiluminescent methods. Archives of medical sciences. 2016; 12: 1071-1076.

8. Прокопьева В.Д., Ярыгина Е.Г., Кротенко Н.М., Бойко А.С., Бохан Н.А., Иванова С.А. Показатели антиоксидантной системы и дофамина плазмы крови в динамике микроволновой резонансной терапии у больных алкоголизмом. Журнал неврологии и психиатрии им. С.С. Корсакова. 2017; 117 (9): C.67-70.

9. Plotnikov E., Voronova O., Linert W., Martemianov D., Korotkova E., Dorozhko E., Astashkina A., Martemianova I., Ivanova S., Bokhan N. Antioxidant and Immunotropic Properties of some Lithium Salts. J. App. Pharm. Sci. 2016; 6: 86-89.

10. Балашов П.П., Аникина Е.Ю., Плотников Е.В., Потапов А.В., Чучалин В.С. Сравнительное изучение нейротоксического действия солей лития. Сибирский вестник психиатрии и наркологии. 2008; 4 (51): 84.

11. Plotnikov E., Prokopieva V., Yarygina E., Losenkov I. Lithium ascorbate as a protector of human blood biomolecules under ethanol impact. National Journal of Physiology, Pharmacy and Pharmacology. 2018; 8: 82-86.

12. Натвиг Д.Б. Лимфоциты, выделение, фракционирование, характеристики. М.: Букинист, 1980: 280.

13. Pohanka M., Pejchal J., Snopkova S., Havlickova K., Karasova J.Z., Bostik P., Pikula J. Ascorbic acid: an old player with a broad impact on body physiology including oxidative stress suppression and immunomodulation: a review. Mini Rev. Med. Chem. 2012; 12: 35-43.

14. Kang J.S., Cho D., Kim Y.I., Hahm E., Kim Y.S., Jin S.N., Kim H.N., Kim D., Hur D., Park H., Hwang Y.I., Lee W.J. Sodium ascorbate (vitamin C) induces apoptosis in melanoma cells via the down-regulation of transferrin receptor dependent iron uptake. J. Cell Physiol. 2005; 204: 192-197.

15. Dutta M., Ghosh A.K., Mishra P., Jain G., Rangari V., Chattopadhyay A., Das T., Bhowmick D., Bandyopadhyay D. Protective effects of piperine against copper-ascorbate induced toxic injury to goat cardiac mitochondria in vitro. Food Funct. 2014; 5: 2252-2267.

16. Littlefield N.A., Hass B.S. Damage to DNA by cadmium or nickel in the presence of ascorbate. Ann. Clin. Lab. Sci. 1995; 25: 485-492.

17. Riordan N.H., Riordan H.D., Meng X., Li Y., Jackson J.A. Intravenous ascorbate as a tumor cytotoxic chemotherapeutic agent. Med Hypotheses. 1995; 44: 207-213.

18. Plotnikov E., Korotkova E., Voronova O., Dorozhko E., Bohan N., Plotnikov S. Lithium-based antioxidants: electrochemical properties and influence on immune cells. Physiologyandpharmacology, 2015; 19: 107-113.

Поступила в редакцию 4.11.2017 Утверждена к печати 5.02.2018

Лосенков Иннокентий Сергеевич, к.м.н., н.с. отделения аффективных состояний. Плотников Евгений Владимирович, к.х.н., с.н.с. отделения эндогенных расстройств Епимахова Елена Викторовна, к.б.н., н.с. отделения аддиктивных состояний.

Лосенков Иннокентий Сергеевич, innokenty86@mail.ru

УДК 616.89:661.834:547.475.2

For citation: Losenkov I.S., Plotnikov E.V., Epimakhova E.V. Study of cytotoxic effect of lithium ascorbate and its influence on oxidative stress in vitro. Siberian Herald of Psychiatry and Addiction Psychiatry. 2018; 1 (98): 24-29. https://doi.org/10.26617/18103111-2018-1(98)-24-29

\title{
Study of cytotoxic effect of lithium ascorbate and its influence on oxidative stress in vitro
}

\section{Losenkov I.S. ${ }^{1}$, Plotnikov E.V. ${ }^{1,2}$, Epimakhova E.V. ${ }^{1}$}

\author{
${ }^{1}$ Mental Health Research Institute, Tomsk National Research Medical Center, Russian Academy of Sciences \\ Aleutskaya Street 4, 634014, Tomsk, Russian Federation \\ ${ }^{2}$ Research School of Chemistry \& Applied Biomedical Sciences, National Research Tomsk Polytechnic University \\ Lenin Avenue 30, 634050, Tomsk, Russian Federation
}

\begin{abstract}
Nowadays there is a study of new promising compounds of lithium with antioxidative properties. Lithium ascorbate is one of these. Assessment of cytotoxic effect and oxidative stress induction by lithium ascorbate and ascorbic acid is made using peripheral blood mononuclear cells as cell model. Strong cytotoxic effect of lithium ascorbate and ascorbic acid manifested by increasing percentage of early apoptotic and late apoptotic/necrotic cells is shown. Induction of oxidative stress (increasing percentage of cell with reactive oxygen species) by these compounds is demonstrated. Following studies in experiments in vitro made on other cell cultures and in vivo studies are needed to evaluate properties of lithium ascorbate as a pharmacological agent.
\end{abstract}

\section{Keywords: lithium, lithium ascorbate, ascorbic acid, oxidative stress, cytotoxicity, apoptosis.}

1. Mashkovskij M.D. Lekarstvennye sredstva: v dvuhc hastjah. Volume 1. 12th ed. Moscow: Medicina, 1986: 544 (in Russian).

2. Freland L., Beaulieu J.M. Inhibition of GSK3 be lithium, from single molecules to signaling networks. Frontiers in molecular neuroscience. 2013; 5: 9-15.

3. Wu J., Zhu D., Zhang J., Li G., Liu Z., Sun J. Lithium protects against methamphetamine-induced neurotoxicity in PC12 cells via Akt/GSK3b/mTOR pathway. Biochem. Biophys. Res. Commun. 2013; 465: 368-373

4. Zheng J., Liu Z., Li W., Tang J., Zhang D., Tang X. Lithium posttreatment confers neuroprotection through glycogen syn- thase kinase-3 $\beta$ inhibition in intracerebral hemorrhage rats. J. Neurosurg. 2017; 127: 716-724.

5. Saberzadeh J., Omrani M., Takhshid M.A. Protective effects of nimodipine and lithium against aluminum-induced cell death and oxidative stress in PC12 cells. Iran J. Basic. Med. Sci. 2016; 19: 1251-1257.

6. da-Rosa D.D., Valvassori S.S., Steckert A.V., Ornell F., Ferreira C.L., Lopes-Borges J. Effects of lithium and valproate on oxidative stress and behavioral changes induced by administration of m-AMPH. Psychiatry Res. 2012; 198: 521-526. 
7. Plotnikov E., Korotkova E., Voronova O., Sazhina N., Petrova E., Artamonov A., Chernyavskaya L., Dorozhko E. Comparative investigation of antioxidant activity of human serum blood by amperometric, voltammetric and chemiluminescent methods. Archives of medical sciences. 2016; 12: 1071-1076.

8. Prokopieva V.D., Jarygina E.G., Krotenko N.M., Boiko A.S., Bokhan N.A., Ivanova S.A. Pokazateli antioksidantnoj sistemy i dofamina plazmy krovi $\mathrm{v}$ dinamike mikrovolnovoj rezonansnoj terapii u bol'nyh alkogolizmom [Indices of the antioxidant system and dopamine in blood plasma in the dynamics of microwave resonance therapy in patients with alcoholism]. Zhurnal nevrologii i psikhiatriiim: S.S. Korsakova - S.S. Korsakov Journal of Neurology and Psychiatry. 2017; 117 (9): 67-70 (in Russian).

9. Plotnikov E., Voronova O., Linert W., Martemianov D., Korotkova E., Dorozhko E., Astashkina A., Martemianova I., Ivanova S., Bokhan N. Antioxidant and Immunotropic Properties of some Lithium Salts. J. App. Pharm. Sci. 2016; 6: 86-89.

10. Balashov P.P., Anikina E.Ju., Plotnikov E.V., Potapov A.V., Chuchalin V.S. Sravnitel'noe izuchenie nejrotoksicheskogo dejstvija solej litija [The comparative study of neurotoxic actions of the salts lithium]. Sibirskij vestnik psihiatrii i narkologii - Siberian Herald of Psychiatry and Addiction Psychiatry. 2008; 4 (51): 84 (in Russian).

11. Plotnikov E., Prokopieva V., Yarygina E., Losenkov I. Lithium ascorbate as a protector of human blood biomolecules under ethanol impact. National Journal of Physiology, Pharmacy and Pharmacology. 2018; 8: 82-86.

12. Natvig D.B. Limfocity, vydelenie, frakcionirovanie, harakteristiki. Moscow: Bukinist; 1980: 280 (in Russian).
13. Pohanka M., Pejchal J., Snopkova S., Havlickova K., Karasova J.Z., Bostik P., Pikula J. Ascorbic acid: an old player with a broad impact on body physiology including oxidative stress suppression and immunomodulation: a review. Mini Rev. Med. Chem. 2012; 12: 35-43.

14. Kang J.S., Cho D., Kim Y.I., Hahm E., Kim Y.S., Jin S.N., Kim H.N., Kim D., Hur D., Park H., Hwang Y.I., Lee W.J. Sodium ascorbate (vitamin C) induces apoptosis in melanoma cells via the down-regulation of transferrin receptor dependent iron uptake. J. Cell Physiol. 2005; 204: 192-197.

15. Dutta M., Ghosh A.K., Mishra P., Jain G., Rangari V., Chattopadhyay A., Das T., Bhowmick D., Bandyopadhyay D. Protective effects of piperine against copper-ascorbate induced toxic injury to goat cardiac mitochondria in vitro. Food Funct. 2014; 5: 2252-2267.

16. Littlefield N.A., Hass B.S. Damage to DNA by cadmium or nickel in the presence of ascorbate. Ann. Clin. Lab. Sci. 1995; 25: $485-492$.

17. Riordan N.H., Riordan H.D., Meng X., Li Y., Jackson J.A. Intravenous ascorbate as a tumor cytotoxic chemotherapeutic agent. Med Hypotheses. 1995; 44: 207-213.

18. Plotnikov E., Korotkova E., Voronova O., Dorozhko E., Bohan N., Plotnikov S. Lithium-based antioxidants: electrochemical properties and influence on immune cells. Physiology and pharmacology, 2015; 19: 107-113.

Received November 4.2017 Accepted February 5.2018

Losenkov Innokentiy S., MD, junior researcher, Affective States Department, Mental Health Research Institute, Tomsk National Research Medical Center, Russian Academy of Sciences, Tomsk, Russian Federation.

Plotnikov Evgeny V. PhD in Chemistry, senior researcher, Mental Health Research Institute, Tomsk National Research Medical Center, Russian Academy of Sciences; Research School of Chemistry \& Applied Biomedical Sciences, National Research Tomsk Polytechnic University, Tomsk, Russian Federation.

Epimakhova Elena V., Candidate of Biological Sciences, researcher, Addictive States Department, Mental Health Research Institute, Tomsk National Research Medical Center, Russian Academy of Sciences, Tomsk, Russian Federation.

Losenkov Innokentiy S., innokenty86@mail.ru 